\title{
Studi Optimasi Pemanfaatan Air Irigasi Pada Daerah Irigasi Gumbasa Kabupaten Sigi Menggunakan Program Linier
}

\author{
Muhammad Qurais Shihab ${ }^{1 *}$, Lily Montarcih L. ${ }^{1}$, Ery Suhartanto ${ }^{1}$ \\ ${ }^{1}$ Jurusan Teknik Pengairan, Fakultas Teknik, Universitas Brawijaya, \\ Jalan MT. Haryono No. 167, Malang, 65145, INDONESIA \\ *Korespondensi Email: muhammadquraish199@ gmail.com
}

\begin{abstract}
Gumbasa irrigated area has a total area of about 1737 hectares it is found several problems such as planting pattern that made by the Water Department which did not come along with the field condition and the water availability in the Gumbasa Dam which is not enough to fulfill the irrigation water needs, especially in the dry season. To fulfill the need for water availability, it needs to optimize the area of the zone which enables to be watered from the existing irrigation availability water by using a linear program to achieve the maximum benefit with the limited availability of resources. This study has a drought problem which solved from $33,3 \%$ of the fulfilled period on average to $100 \%$ in a year, planting intensity from $40,97 \%$ to $165,177 \%$, and the increased net income from Rp7.815.404.895,00 to Rp32.969.542.295,00 per year with the condition of $97 \%$ of the dependable flow. while in the condition of $80 \%$ of the dependable flow from $79,17 \%$ period is fulfilled to $100 \%$, planting intensity from $106,94 \%$ to $262,5 \%$ with the increased net income from Rp20.399.617.696,00 to Rp49.682.562,315,00 per year. for the condition of $75 \%$ of the dependable flow to $91,68 \%$ period fulfilled to $100 \%$, planting intensity $124,58 \%$ to $247,44 \%$ with the increased net income from Rp23.765.038.614,00 to maximum income in Rp50.135.817.479,00. for the condition of 50\% of dependable flow and $30 \%$ was not optimized because of the water availability fulfilled the irrigation needs.
\end{abstract}

Keywords: Irrigation Area, Irrigation Water, Net Income, Optimizing

Abstrak: Daerah Irigasi Gumbasa memiliki luas baku sawah sebesar 1737 hektar. ditemukan beberapa permasalahan seperti pola tata tanam yang dibuat oleh Dinas Pengairan tidak sejalan dengan kondisi lapangan serta air yang tersedia di Bendung Gumbasa tidak mencukupi untuk memenuhi kebutuhan air irigasi pada musim kemarau. Agar ketersediaan air dapat mencukupi kebutuhan diperlukan pengoptimalan luas areal yang dapat terairi dari ketersediaan air irigasi yang ada dengan menggunakan program linier agar dapat diperoleh manfaat maksimal dengan keterbatasan sumber daya yang ada. Studi ini mempunyai masalah kekeringan pada rata - rata dalam setahun dapat teratasi berawal dari $33,3 \%$ periode tercukupi menjadi $100 \%$, intensitas tanam $40,97 \%$ menjadi $165,177 \%$ serta keuntungan bersih yang meningkat dari Rp. 7.815.404,895 Per tahun menjadi Rp. 32.969.542,295 dengan 
kondisi debit andalan $97 \%$. Sedangkan pada kondisi debit andalan $80 \%$ berawal dari $79,17 \%$ periode tercukupi menjadi $100 \%$, intensitas tanam dari $106,94 \%$ menjadi $262,5 \%$ serta keuntungan bersih yang meningkat dari Rp. 20.399.617,696 per tahun menjadi Rp. 49.682.562,315. Untuk kondisi debit andalan 75\% berawal dari 91,68\% periode terpenuhi menjadi $100 \%$, intensitas tanam $124,58 \%$ menjadi $247,44 \%$ serta keuntungan bersih yang meningkat dari Rp. 23.765.038,614 menjadi keuntungan maksimum yaitu Rp. 50.135.817,479. Untuk kondisi debit andalan 50\% dan 30\% tidak di optimasi dikarenakan ketersediaan airnya memenuhi kebutuhan air irigasi.

Kata Kunci: Air Irigasi, Daerah Irigasi, Keuntungan Bersih, Optimasi.

\section{Pendahuluan}

Daerah Irigasi Sungai (DAS) merupakan daerah dimana semua hujan efektif yang melimpas di atas permukaan tanah akan mengalir ke sungai yang bersangkutan. Daerah ini dibatasi oleh batas topografi (garis kontur) yang berarti ditetapkan berdasarkan limpasan dan dibatasi oleh titik kontrol outlet yang umumnya merupakan stasiun hidrometri atau lokasi bangunan air. DAS memiliki maksud sebagai kehidupan bagi makhluk hidup seperti manusia, hewan dan tumbuhan yang membutuhkan air sesuai dengan kebutuhannya untuk kelangsungan hidup. Manusia membutuhkan air hampir dim semua sisi kehidupan, baik itu untuk menanaman tanaman, minum, memasak, mencuci dan lain sebagainya, dengan berkembangannya kebutuhan air memerlukan perhitungan hidrologi untuk mengetahui ketersediaan air dan pemanfaatan air. DAS merupakan salah satu pemanfaatan air, yang dapat mensuplai air yang dibutuhkan oleh kepentingan manusia [1].

Salah satu untuk mencari kebutuhan air irigasi yaitu dengan menganalisa curah hujan, curah hujan diperlukan untuk suatu pemanfaatan air yang salah satunya seperti alokasi air irigasi dengan mencari hujan rata - rata di seluruh daerah yang bersangkutan, curah hujan ini disebut curah hujan wilayah/daerah yang harus diperkirakan dari beberapa titik pengamatan curah hujan. Curah hujan merupakan jumlah air yang jatuh di permukaan bumi selama satu periode tertentu yang bisa diukur dalam satuan milimeter $(\mathrm{mm})$. tidak semua curah hujan yang jatuh ke permukaan bumi dimanfaatkan untuk pertumbuhan tanaman. Sebagian mengalir sebagai limpasan permukaan, sebagian lagi akan menguap di udara [2].

Di dalam dunia pertanian, untuk mencapai produk yang baik dan berkualitas, diperlukan dukungan dari beberapa faktor, mulai dari kualitas pupuk yang baik sampai pemberian air irigasi yang sesuai dengan kebutuhannya tidak lebih maupun tidak kurang. Untuk objek pembahasan ini penulis lebih memperdalam faktor irigasinya, dalam pemberian air yang sesuai kebutuhannya dan mencari keuntungan petani yang maksimal dengan modal yang minimal.

Menurut peraturan Pemerintah nomor 23 ayat 1 tahun 1982, tujuan irigasi disediakan dan dimanfaatkan adalah untuk memperoleh hasil produksi yang optimal dari seluruh usaha pertanian yang mendapatkan manfaat dari air irigasi. Sedangkan peraturan pemerintah nomor 23 ayat 2 tahun 1982, maksud irigasi adalah untuk dapat memenuhi air bagi usaha pertanian dalam jumlah dan waktu yang diperlukan sesuai dengan kebutuhan bagi semua tanaman menurut aturan yang telah ditetapkan. [3]

Peningkatan produktifitas serta perbaikan taraf hidup petani merupakan tujuan akhir dari pembangunan maupun rehabilitasi suatu sistem irigasi. Pada daerah dengan iklim kering, irigasi mutlak diperlukan untuk meningkatkan produksivitas daerah tersebut. Bagi daerah yang mendapatkan pengairan secara alami (hujan) secara baik, maka dengan adanya irigasi produktivitas dapat ditingkatkan. Nyata sekali bahwa sumbangan irigasi terhadap keperluan daerah pertanian sangat besar, dimana daerah yang mulanya kurang produktif akan menjadi potensial. [4]

Pengelolaan air irigasi yang baik sejalan dengan peningkatan produksi daerah irigasi. Pola tata tanam adalah sistem perdistribusian berbagai jenis tanaman yang ditanam dalam satu satuan yang 
luasnya bergantung pada satu musim tanam, sedangkan pola tanam adalah susunan suatu tanaman yang akan diusahakan dalam suatu luasan pada satu tahuan. Tujuan dari pola tata tanam tak lain untuk memanfaatkan persediaan air irigasi semaksimal mungkin sehingga tanaman dapat tumbuh dengan baik. Metode optimasi menjadi salah satu yang baik dalam mengatur pola tata tanam agar mencapai hasil yang ideal dalam mengoptimalkan sumber daya pertanian yang ada dengan cara merancang dan membuat pola tata tanam secara optimal dengan judul penelitian Studi Optimasi Pemanfaatan Air Irigasi pada Daerah Irigasi Gumbasa Kabupaten Sigi Menggunakan Program Linier.

Tujuan penelitian ini mengetahui jumlah pola tata tanam dan alternatifnya serta mengetahui kondisi debit andalan yang akan di analisa dengan maksud ketika terjadi defisit air pada kondisi eksisting gumbasa, dibuat alternatif - alternatif dengan maksud mengurangi atau menggantikan pola tata tanam eksisting yang tujuannya agar kondisi ketersediaan dan kebutuhannya terpenuhi di alternatif tersebut. Serta mengetahui berapa besar produksi pertanian dengan maksud mencari keuntungan paling maksimum di setiap kondisi debit andalan serta alternatif - alternatifnya.

\section{Bahan dan Metode}

\subsection{Bahan}

Penelitian ini dilakukan di Daerah Irigasi Gumbasa Kabupaten Sigi, secara Administrasi berada di 5 (lima) Wilayah Kecamatan, meliputi:

1. Kecamatan Gumbasa (Desa Pandere dan Desa Kalawara)

2. Kecamatan Tanambulava (Desa Lambara, Sibalaya, Sibalaya Selatan, Sibowi dan Desa Sidondo

3. Kecamatan Sigi Biromaru (Desa Sidondo)

4. Kabupaten Sigi

5. Palu Selatan

Daerah Irigasi Gumbasa secara Geografis terletak di $0^{\circ} 3^{\prime \prime}$ LU dan $2^{\circ} 2^{\prime \prime}$ LS, serta antara $119^{\circ} 45^{\prime \prime}$ - $122^{\circ} 45^{\prime \prime}$ BT. Adanya endapan erosi dari tahun ke tahun menyebabkan perubahan tata guna lahan menjadi faktor yang sering di temui seiring dengan meningkatnya aktivitas manusia itu sendiri, yang mana masyarakat yang mata pencahariannya terbesar adalah petani yang membutuhkan pengembangan pertanian dan menjadikan lahan kawasan persawahan menjadi kawasan pemukiman sehingga ketika ada fluktuasi curah hujan dapat meningkatkan volume limpasan permukaan dan debit pada bagian hilir sungai. Kondisi ini menyebabkan berkurangnya daerah resapan air sehingga berpengaruh terhadap debit yang masuk ke sungai.

Kondisi Topografi Daerah Irigasi Gumbasa termasuk daerah dataran tinggi di sisi timur dan satuan pedataran ke arah barat, Kondisi Iklim di Gumbasa dengan Intensitas hujan di Kabupaten Sigi cukup tinggi yaitu rata - rata 90 hari hujan per tahun dengan curah hujan $1365 \mathrm{~mm}$ per tahun. Untuk Kondisi umum lokasi Studi Daerah Irigasi Gumbasa memanfaatkan sumber air dari Sungai Gumbasa melalui Bendung Gumbasa sebagai bangunan penangkap airnya, mengalirkan air dengan sistem gravitasi untuk mengalii areal pertanian pekerjaan SID Rehabilitasi daerah irigasi Gumbasa yang memiliki luas areal seluas 1.737 Ha. Daerah irigasi Gumbasa terletak di area lembah Palu. Sungai Gumbasa mengalir hingga Sungai Kawatuna di Kota Palu. Bangunan Utama pemasok air adalah Bendung Gumbasa yang terletak di Desa Gumbasa yang terletak di Desa Pandere Kecamatan Gumbasa, tempat ini dapat dicapai dengan menggunakan kendaraan roda empat karena terdapat jalan inspeksi di sepanjang saluran primer.

Dengan adanya pembangunan dan pengembangan di Kabupaten Sigi dan Kota Palu, hal ini akan berdampak pada luas areal potensial Daerah Irigasi Gumbasa, baik alih fungsi lahan maupun ketersediaan airnya. Dengan demikian diperlukan suatu kegiatan studi dan desain kembali jaringan irigasi gumbasa sesuai dengan kondisi saat ini dengan melakukan studi optimasi pada daerah irigasi ini dengan harapan mencari keuntungan paling maksimum dengan ketersediaan dan kebutuhan air yang ada pada Daerah Irigasi Gumbasa dengan dianalisa menggunakan data - data terbaru. Berikut merupakan daftar desa yang menjadi lokasi atau titik peneltian, yaitu : 


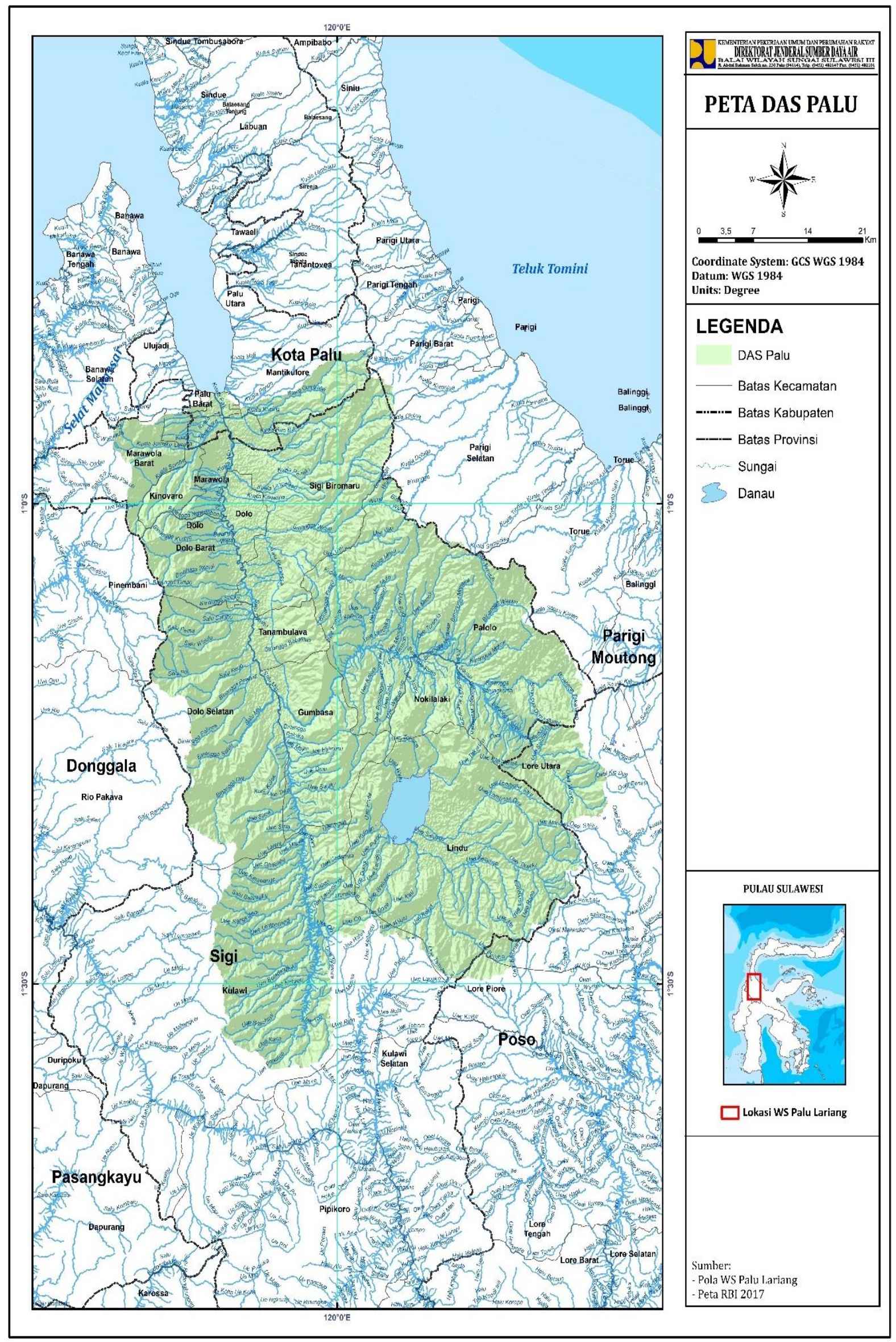

Gambar 1. Peta Daerah Aliran Sungai Palu, Sulawesi Tengah 
Data yang diperoleh pada penelitian ini ada dua tipe data, yaitu data primer dan sekunder untuk analasis. Data primer merupakan data yang diperoleh dari hasil pengukuran atau pengamatan, sedangkan data sekunder adalah data yang diperoleh dari mengutip berbagai sumber yang dapat dipertanggungjawabkan kebenarannya, data yang diperoleh didapatkan dari Balai Wilayah Sungai Sulawesi III yaitu :

- Data Curah Hujan dan Data Debit Intake Gumbasa yang di analisis selama 10 tahun dimulai dari tahun 2010 sampai dengan 2019.

- Data Jenis Tanah yang akan dipakai untuk mencari nilai WLR (Pergantian Lapisan Air) dan perkolasi dari Daerah irigasi sekitat yang diperlukan untuk menghitung kebutuhan air irigasi

- Data Klimatologi yang di analisis selama 10 tahun terakhir yang terdiri dari suhu rata - rata bulanan, data kecepatan angin rerata bulanan, data radiasi sinar matahari dan Kelembapan udara. Data ini diperlukan untuk menghitung besarnya evapotranspirasi potensial yang terjadi di daerah tersebut

- Data Pola Tata Tanam yang berfungsi untuk melihat jadwal tanam di setiap periode dan Tanaman apa saja yang akan di tanami di Daerah Irigasi tersebut.

- Data Ekonomi Usaha Tani berupa hasil produksi pertanian seperti (harga produk, produktivitas, biaya produksi dan keuntungan bersih) yang berfungsi untuk menganalisa optimasi dengan program linier.

- Skema Jaringan Irigasi yang bertujuan untuk mengetahui luas lahan pertanian yang akan dialiri.

Alat Bantu yang akan digunakan pada penelitian ini yaitu perangkat lunak Microsoft Excel yang berfungsi untuk program optimasi linier sehingga diperoleh keuntungan maksimal.

\subsection{Metode}

Sebelum dilakukan penelitian, dikumpulkan data berupa data curah hujan, data debit intake, data jenis tanah, data klimatologi, data pola tata tanam, data ekonomi usaha tani dan skema jaringan irigasi. Data curah hujan kemudian diolah dengan analisis kualitas data yang terdiri dari uji konsistensi, uji stasioner, uji ketidakadaan tren dan uji persistensi. Pada DAS Gumbasa, di analisis hujan rerata daerahnya menggunakan metode Rerata Arikmatika, data curah hujan tersebut dipakai untuk mencari curah hujan efektif yang berfungsi untuk menyusun pola tata tanam. Selanjutnya yaitu analisis debit andalan dengan menggunakan metode bulan dasar (Basic Month) yang hasilnya akan berfungsi untuk ketersediaan air dengan resiko kegagalan yang telah diperhitungkan. Kemudian menganalisis data Klimatologi yang hasilnya akan berfungsi untuk mendapatkan ETo (Evapotranspirasi Potensial) dan PL (Penyiapan Lahan) yang berfungsi untuk menentukan kebutuhan air dalam merencanakan pola tata tanam. Setelahnya menyusun pola tata tanam yang datanya didapat dari evapotranspirasi potensial, penyiapan lahan dan curah hujan efektif, setelah di analisa akan mendapatkan kebutuhan air dan dibandingkan dengan ketersediaan air yang ada. Ketika dibandingkan ketersediaan air dan kebutuhan airnya terjadi defisit air, maka dari itu perlu di optimasi agar ketersediaan air yang ada dapat mencukupi kebutuhan air irigasi sehingga didapatkan hasil keuntungan produksi pertanian yang optimal, untuk kondisi ketersediaan dan kebutuhan air yang terpenuhi, tidak dilakukan optimasi dikarenakan ketersediaan dan kebutuhan air lebih mencukupi dari pada kebutuhan air yang telah direncanakan. Kemudian melakukan optimasi program linier memakai alpikasi Microsoft Excel dengan variabel yang ada untuk mengoptimalkan ketersediaan air, intensitas tanaman dan harga produksi. Dan yang terakhir menentukan pola tata tanam yang paling efektif yang akan dipilih paling efektif berdasarkan keuntungan produksi dan intensitas tanamnya.

\section{Hasil dan Pembahasan}

\subsection{Analisis Kualitas Data}

Analisis kualitas data diperlukan untuk memeriksa data tersebut yang bertujuan untuk mengetahui kualitas data hidrologi secara statistik karena memungkinkan adanya gangguan dalam proses pengambilan data di lapangan. [5] 


\subsubsection{Pengujian Konsistensi Metode Kurva Massa Ganda}

Uji Konsistensi metode Kurva Massa ganda pada curah hujan di 4 stasiun di DAS Gumbasa menghasilkan data yang konsisten sehingga layak digunakan pada proses analisa berikutnya.

Tabel 1: Uji Kurva Massa Ganda

\begin{tabular}{ccccc}
\hline \multirow{2}{*}{ Tahun } & \multicolumn{4}{c}{ Curah Hujan Tahunan Per Stasiun } \\
\cline { 2 - 5 } & $\begin{array}{c}\text { Bangga } \\
\text { Bawah }\end{array}$ & Palolo & Sibalaya & Sibowi \\
\hline 2019 & 1408 & 1177 & 1404 & 1460 \\
2018 & 2876 & 2529 & 2831 & 2882 \\
2017 & 4662 & 4129 & 4663 & 4798 \\
2016 & 5197 & 4696 & 5243 & 5471 \\
2015 & 6428 & 5615 & 6469 & 6602 \\
2014 & 7684 & 6349 & 7384 & 7526 \\
2013 & 9126 & 7393 & 8801 & 8660 \\
2012 & 10191 & 8264 & 9789 & 9576 \\
2011 & 10992 & 9040 & 10569 & 10359 \\
2010 & 12039 & 10096 & 11628 & 11481 \\
\hline Keterangan & Konsisten & Konsisten & Konsisten & Konsisten \\
\hline
\end{tabular}

\subsubsection{Pengujian Stasioner}

Pengujian F dan Uji T dengan derajat kepercayaan 5\% menunjukkan bahwa data curah hujan pada 4 stasiun di DAS Gumbasa bersifat stabil terhadap nilai rerata dan varian.

Tabel 2: Uji Stasioner

\begin{tabular}{ccccccc}
\hline No & Nama Stasiun & F Hitung & Fc & T hitung & Tc & Keterangan \\
\hline 1 & Bangga Bawah & 0.268 & 6.39 & 0.624 & 1.86 & Homogen \\
2 & Palolo & 0.140 & 6.39 & 1.067 & 1.86 & Homogen \\
3 & Sibalaya & 0.274 & 6.39 & 1.526 & 1.86 & Homogen \\
4 & Sibowi & 0.107 & 6.39 & 1.430 & 1.86 & Homogen \\
\hline
\end{tabular}

\subsubsection{Pengujian Ketidakadaan Tren}

Dalam analisis ini menunjukan tidak adanya tren di suatu deret berkala, maka analisis ini dapat digunakan pada pengujian selanjutnya.

Tabel 3: Uji Ketidakadaan Tren

\begin{tabular}{cccc}
\hline T hitung & 0 & $\mathrm{t} 5 \%$ & Kesimpulan \\
\hline$-17,000$ & -1.86 & 1.86 & $\begin{array}{c}\text { tidak menunjukan } \\
\text { adanya tren }\end{array}$ \\
\hline
\end{tabular}

\subsubsection{Pengujian Persistensi}

Dalam analisis uji ini data menunjukan tidak adanya persistensi sehingga data bersifat acak. Maka semua data dapat digunakan untuk menganalisis curah hujan efektif.

\section{Tabel 4: Uji Persistensi}

\begin{tabular}{cccc}
\hline T hitung & 0 & $\mathrm{t} 5 \%$ & Kesimpulan \\
\hline-0.493 & -1.86 & 1.86 & Data Persisten \\
\hline
\end{tabular}




\subsection{Analisa Hidrologi}

Curah Hujan daerah digunakan untuk mencari rancangan distribusi pemanfaatan sumber daya air untuk kebutuhan air irigasi. Ini dikarenakan curah hujan pada setiap luasan harus diperkirakan titik titik pengamatan lewat stasiun hujan. Data curah hujan yang diperlukan sedikitnya 10 tahun untuk dianalisa agar mendapatkan perhitungan curah hujan efektif dapat diterima [6]. Dalam skripsi ini perhitungan curah hujan daerah memakai analisa poligon thiessen. Berikut merupakan hasil perhitungan koefisien thiessen.

Tabel 5: Hasil Analisis Koefisien Thiessen

\begin{tabular}{cccc}
\hline \multirow{2}{*}{ Stasiun Hujan } & $\begin{array}{c}\text { Luas } \\
\text { Wilayah }\end{array}$ & $\begin{array}{c}\text { Koefisien } \\
\text { Thiessen }\end{array}$ & $\begin{array}{c}\text { Porsentase } \\
\text { Pengaruh }\end{array}$ \\
\cline { 2 - 4 } & $\mathrm{Km}^{2}$ & $(\mathrm{Kr})$ & $(\%)$ \\
\hline Bangga Bawah & 76.700 & 0.310 & 30.977 \\
Sibalaya & 15.900 & 0.064 & 6.422 \\
Sibowi & 59.900 & 0.242 & 24.192 \\
Palolo & 95.100 & 0.384 & 38.409 \\
Jumlah & 247.600 & 1.000 & 100.000 \\
\hline
\end{tabular}

\subsection{Perhitungan Evapotranspirasi Potensial}

Perhitungan evapotranspirasi potensial menggunakan metode Penman Modifikasi sesuai yang ditetapkan oleh Standar Kriteriia Perencanaan Irigasi (KP-01) dan Food and Agriculture Organization (FAO). Metode ini mempunyai parameter lebih banyak sehingga dianggap paling efektif. Dalam perhitungan evapotranspirasi potensial membutuhkan data klimatologi seperti kelembapan udara, kecepatan angin, lama penyinaran matahari dan temperatur udara [7]. Data klimatologi yang digunakan adalah data klimatologi bulanan selama 10 tahun terakhir (2010-2019). Data ini diperoleh dari stasiun meteorologi terdekat yang datanya bisa digunakan dan data tersebut didapatkan dari Balai Wilayah Sungai Sulawesi III. Untuk hasil perhitungannya dapat dilihat pada tabel dibawah ini.

Tabel 6: Hasil Perhitungan Evapotranspirasi Potensial

\begin{tabular}{|c|c|c|c|c|c|}
\hline Bulan & Satuan & $\begin{array}{c}\text { Evapotranspirasi } \\
\text { Potensial } \\
\end{array}$ & Bulan & Satuan & $\begin{array}{c}\text { Evapotranspirasi } \\
\text { Potensial } \\
\end{array}$ \\
\hline \multirow{2}{*}{ Jan } & $\mathrm{mm} / \mathrm{hari}$ & 2.898 & \multirow{2}{*}{ Jul } & $\mathrm{mm} / \mathrm{hari}$ & 2.242 \\
\hline & $\mathrm{mm} / \mathrm{bulan}$ & 89.833 & & $\mathrm{~mm} / \mathrm{bulan}$ & 69.499 \\
\hline \multirow{2}{*}{$\mathrm{Feb}$} & $\mathrm{mm} / \mathrm{hari}$ & 3.024 & \multirow{2}{*}{ Agust } & $\mathrm{mm} / \mathrm{hari}$ & 2.738 \\
\hline & $\mathrm{mm} / \mathrm{bulan}$ & 93.750 & & $\mathrm{~mm} / \mathrm{bulan}$ & 84.876 \\
\hline \multirow{2}{*}{ Mar } & $\mathrm{mm} / \mathrm{hari}$ & 3.064 & \multirow{2}{*}{ Sept } & $\mathrm{mm} / \mathrm{hari}$ & 3.033 \\
\hline & $\mathrm{mm} / \mathrm{bulan}$ & 94.975 & & $\mathrm{~mm} / \mathrm{bulan}$ & 94.021 \\
\hline \multirow{2}{*}{ Apr } & $\mathrm{mm} / \mathrm{hari}$ & 2.559 & \multirow{2}{*}{ Okt } & $\mathrm{mm} / \mathrm{hari}$ & 3.260 \\
\hline & $\mathrm{mm} / \mathrm{bulan}$ & 79.338 & & $\mathrm{~mm} / \mathrm{bulan}$ & 101.073 \\
\hline \multirow{2}{*}{ Mei } & $\mathrm{mm} / \mathrm{hari}$ & 2.277 & \multirow{2}{*}{ Nov } & $\mathrm{mm} / \mathrm{hari}$ & 2.881 \\
\hline & $\mathrm{mm} / \mathrm{bulan}$ & 70.575 & & $\mathrm{~mm} / \mathrm{bulan}$ & 89.315 \\
\hline \multirow{2}{*}{ Jun } & $\mathrm{mm} / \mathrm{hari}$ & 2.217 & \multirow{2}{*}{ Des } & $\mathrm{mm} / \mathrm{hari}$ & 2.945 \\
\hline & $\mathrm{mm} / \mathrm{bulan}$ & 68.717 & & $\mathrm{~mm} / \mathrm{bulan}$ & 91.284 \\
\hline
\end{tabular}




\subsection{Perhitungan Curah Hujan Efektif}

Curah Hujan Efektif adalah sejumlah curah hujan yang jatuh pada suatu daerah dan dapat digunakan oleh tanaman untuk pertumbuhannya [8]. Besarnya curah hujan dapat dimanfaatkan untuk memenuhi kebutuhan air pertanian sehingga dapat memperkecil debit yang diperlukan dari pintu pengambilan. Jumlah curah hujan yang turun tidak semuanya dapat dimanfaatkan untuk tanaman dalam pertumbuhannya. Oleh karena itu perlu memperhitungkan curah hujan yang memungkinkan terpenuhi dengan perluang kejadian tertentu dan ditentukan curah hujan yang efektif untuk pertumbuhan tanaman. [8]

Dasar perhitungan untuk menentukan curah hujan andalan dan curah hujan efektif yaitu menggunakan data curah hujan periode 15 harian (dari tahun 2010-2019) yang dirata - ratakan per bulan dari 4 stasiun yaitu Stasiun Bangga bawah, Palolo, Sibowi dan Sibalaya. Setelah di analisis didapatkan data curah hujan probabilitas R80\% pada tahun 2012. Berikut merupakan perhitungan curah hujan efektif untuk Tanaman padi dan Palawija.

Tabel 7: Perhitungan Curah Hujan Efektif untuk Tanaman Padi dan Palawija

\begin{tabular}{|c|c|c|c|c|}
\hline \multirow{2}{*}{ Bulan } & & \multirow{2}{*}{$\begin{array}{l}R_{80} \\
\mathrm{~mm}\end{array}$} & \multicolumn{2}{|c|}{$\operatorname{Reff}(\mathrm{mm} / \mathrm{hari})$} \\
\hline & & & Padi & Palawija \\
\hline \multirow{2}{*}{ Januari } & I & 6.886 & 0.321 & 0.011 \\
\hline & II & 2.300 & 0.107 & 0.011 \\
\hline \multirow{2}{*}{ Februari } & I & 5.855 & 0.273 & 0.002 \\
\hline & II & 5.462 & 0.255 & 0.002 \\
\hline \multirow{2}{*}{ Maret } & I & 9.503 & 0.443 & 0.012 \\
\hline & II & 2.649 & 0.124 & 0.012 \\
\hline \multirow{2}{*}{ April } & I & 14.939 & 0.697 & 0.010 \\
\hline & II & 5.746 & 0.268 & 0.010 \\
\hline \multirow{2}{*}{ Mei } & I & 0.592 & 0.028 & 0.008 \\
\hline & II & 3.108 & 0.145 & 0.008 \\
\hline \multirow{2}{*}{ Juni } & I & 10.123 & 0.472 & 0.017 \\
\hline & II & 9.697 & 0.453 & 0.017 \\
\hline \multirow{2}{*}{ Juli } & I & 15.247 & 0.712 & 0.023 \\
\hline & II & 12.008 & 0.560 & 0.023 \\
\hline \multirow{2}{*}{ Agustus } & I & 10.018 & 0.467 & 0.042 \\
\hline & II & 14.859 & 0.693 & 0.042 \\
\hline \multirow{2}{*}{ September } & I & 9.094 & 0.424 & 0.002 \\
\hline & II & 1.878 & 0.088 & 0.002 \\
\hline \multirow{2}{*}{ Oktober } & I & 6.586 & 0.307 & 0.017 \\
\hline & II & 12.210 & 0.570 & 0.017 \\
\hline \multirow{2}{*}{ November } & I & 19.906 & 0.929 & 0.030 \\
\hline & II & 18.436 & 0.860 & 0.030 \\
\hline \multirow{2}{*}{ Desember } & I & 25.023 & 1.168 & 0.032 \\
\hline & II & 23.198 & 1.083 & 0.032 \\
\hline
\end{tabular}




\subsection{Penyiapan Lahan}

Untuk perhitungan kebutuhan air irigasi selama penyiapan lahan, digunakan metode yang dikembangkan oleh Van de Goor dan Zijltra, metode tersebut didasarkan pada laju konstan dalam 1t/dt selama periode penyiapan lahan [9]. Berikut merupakan hasil perhitungan kebutuhan air untuk pernyiapan lahan.

Tabel 8: Hasil Perhitungan Kebutuhan air untuk Penyiapan Lahan

\begin{tabular}{|c|c|c|c|c|c|c|c|c|c|c|c|c|c|}
\hline \multirow{2}{*}{ Parameter } & \multirow{2}{*}{ Satuan } & \multicolumn{12}{|c|}{ Bulan } \\
\hline & & 1 & 2 & 3 & 4 & 5 & 6 & 7 & 8 & 9 & 10 & 11 & 12 \\
\hline ETo & $\mathrm{mm} / \mathrm{hari}$ & 2.9 & 3.0 & 3.1 & 2.6 & 2.3 & 2.2 & 2.2 & 2.7 & 3.0 & 3.3 & 2.9 & 2.9 \\
\hline$E o=$ ETo $.1,1$ & $\mathrm{~mm} / \mathrm{hari}$ & 3.2 & 3.3 & 3.4 & 2.8 & 2.5 & 2.4 & 2.5 & 3.0 & 3.3 & 3.6 & 3.2 & 3.2 \\
\hline$P$ & $\mathrm{~mm} / \mathrm{hari}$ & 3.0 & 3.0 & 3.0 & 3.0 & 3.0 & 3.0 & 3.0 & 3.0 & 3.0 & 3.0 & 3.0 & 3.0 \\
\hline$M=E o+P$ & $\mathrm{~mm} / \mathrm{hari}$ & 6.2 & 6.3 & 6.4 & 5.8 & 5.5 & 5.4 & 5.5 & 6.0 & 6.3 & 6.6 & 6.2 & 6.2 \\
\hline$T$ & hari & 30 & 30 & 30 & 30 & 30 & 30 & 30 & 30 & 30 & 30 & 30 & 30 \\
\hline$S$ & $\mathrm{~mm}$ & 300 & 300 & 300 & 300 & 300 & 300 & 300 & 300 & 300 & 300 & 300 & 300 \\
\hline$k=(M . T) / S$ & & 0.6 & 0.6 & 0.6 & 0.6 & 0.6 & 0.5 & 0.5 & 0.6 & 0.6 & 0.7 & 0.6 & 0.6 \\
\hline$e^{k}$ & & 1.9 & 1.9 & 1.9 & 1.8 & 1.7 & 1.7 & 1.7 & 1.8 & 1.9 & 1.9 & 1.9 & 1.9 \\
\hline \multirow{2}{*}{$I R: M e^{k} /\left(e^{k}-1\right)$} & $\mathrm{mm} / \mathrm{hari}$ & 13.4 & 13.5 & 13.5 & 13.2 & 13.0 & 13.0 & 13.0 & 13.3 & 13.5 & 13.7 & 13.4 & 13.4 \\
\hline & 1/dt/ha & 1.6 & 1.6 & 1.6 & 1.5 & 1.5 & 1.5 & 1.5 & 1.5 & 1.6 & 1.6 & 1.6 & 1.6 \\
\hline
\end{tabular}

\subsection{Pola Tata Tanam}

Pada lokasi studi Daerah Irigasi Gumbasa dengan luas lahan 1737 Ha, pola tata tanam eksisting metode PU berdsarkan Rencana tata tanam Global (RTTG) Balai Wilayah Sungai Sulawesi III direncanakan yang ditanami yaitu Padi dan Palawija (Jagung dan Kacang Tanah). Komposisi luas tanam pada kondisi eksisting dapat dilihat sebagai berikut.

1. Musim Tanam I (MT 2)

Awal Mulai tanam untuk musim tanam I pada Oktober Periode I dengan detail sebagai berikut:

- Padi

$$
=1390 \mathrm{Ha}
$$

- Palawija

$$
=347 \mathrm{Ha}
$$

2. Musim Tanam II (MT 2)

Awal musim tanam untuk musim tanam I pada Januari Periode II dengan detail sebagai berikut:

- Padi

$$
\begin{aligned}
& =1390 \mathrm{Ha} \\
& =347 \mathrm{Ha}
\end{aligned}
$$

- Palawija

3. Musim Tanam III (MT 3)

Awal mulai tanam untuk musim tanam III pada Juni Periode 1 dengan detail sebagai berikut:

- Padi

$$
\begin{aligned}
& =1390 \mathrm{Ha} \\
& =347 \mathrm{Ha}
\end{aligned}
$$

- Palawija

\subsection{Hasil Neraca Air Sebelum di Optimasi}

Analisis neraca air dilakukan dengan membandingkan kebutuhan air irigasi dengan berbagai alternatif pola tata tabam dengan ketersediaan air keandalan 97\%, 80\%, 75\%, 50\% dan 30\%. Dengan adanya neraca air kekurangan dan kelebihan air dapat dilihat kebutuhan dan ketersediaan air yang ada di Daerah irigasi tersebut. 
Tabel 9: Hasil Neraca Air Sebelum di Optimasi kondisi 97\%

\begin{tabular}{|c|c|c|c|c|c|c|c|c|}
\hline \multirow{4}{*}{ Bulan } & \multirow{4}{*}{$\operatorname{Tr}$} & \multirow{4}{*}{$\begin{array}{c}\text { Ketersediaan } \\
\text { Air Irigasi } \\
\left(\mathrm{m}^{3} / \text { detik }\right)\end{array}$} & \multicolumn{6}{|c|}{ Kebutuhan Air Irigasi } \\
\hline & & & \multicolumn{6}{|c|}{$\left(\mathrm{m}^{3} /\right.$ detik $)$} \\
\hline & & & \multicolumn{6}{|c|}{ Sebelum Optimasi } \\
\hline & & & Eksisting & Alternatif 1 & Alternatif 2 & Alternatif 3 & Alternatif 4 & Alternatif 5 \\
\hline \multirow{2}{*}{ Sept } & $\mathrm{I}$ & 0.129 & 0.692 & 1.694 & 0.356 & 0.782 & 0.403 & 0.625 \\
\hline & II & 0.315 & 1.324 & 3.337 & 0.315 & 1.655 & 0.359 & 1.324 \\
\hline \multirow{2}{*}{ Okt } & $\mathrm{I}$ & 0.161 & 1.416 & 3.606 & 0.383 & 1.756 & 0.419 & 1.756 \\
\hline & II & 0.118 & 0.974 & 2.509 & 0.671 & 1.167 & 0.671 & 1.167 \\
\hline \multirow{2}{*}{ Nov } & $\mathrm{I}$ & 0.124 & 0.706 & 1.885 & 0.746 & 0.799 & 0.746 & 0.799 \\
\hline & II & 0.163 & 0.818 & 2.091 & 0.859 & 0.912 & 0.859 & 0.912 \\
\hline \multirow{2}{*}{ Des } & I & 0.229 & 0.786 & 2.094 & 0.813 & 0.866 & 0.813 & 0.866 \\
\hline & II & 0.425 & 0.531 & 1.443 & 0.527 & 0.554 & 0.527 & 0.554 \\
\hline \multirow{2}{*}{ Jan } & I & 0.863 & 0.712 & 1.719 & 0.363 & 0.659 & 0.363 & 0.821 \\
\hline & II & 0.968 & 1.356 & 3.310 & 0.298 & 1.344 & 0.298 & 1.674 \\
\hline \multirow{2}{*}{ Feb } & I & 1.033 & 1.444 & 3.558 & 0.377 & 1.444 & 0.377 & 1.809 \\
\hline & II & 1.104 & 1.050 & 2.527 & 0.736 & 1.050 & 0.736 & 1.318 \\
\hline \multirow{2}{*}{ Mar } & $\mathrm{I}$ & 0.903 & 0.503 & 1.185 & 0.510 & 0.503 & 0.510 & 0.621 \\
\hline & II & 0.836 & 0.657 & 1.459 & 0.696 & 0.657 & 0.696 & 0.803 \\
\hline \multirow{2}{*}{ Apr } & I & 1.081 & 0.807 & 2.085 & 0.992 & 0.806 & 0.992 & 0.990 \\
\hline & II & 1.294 & 0.657 & 1.617 & 0.796 & 0.657 & 0.796 & 0.767 \\
\hline \multirow{2}{*}{ Mei } & $\mathrm{I}$ & 1.050 & 0.737 & 1.779 & 0.449 & 0.737 & 0.449 & 0.885 \\
\hline & II & 1.325 & 1.264 & 3.204 & 0.272 & 1.263 & 0.272 & 1.579 \\
\hline \multirow{2}{*}{ Jun } & I & 1.050 & 1.269 & 3.299 & 0.236 & 1.576 & 0.236 & 1.179 \\
\hline & II & 0.217 & 0.849 & 2.193 & 0.532 & 1.027 & 0.530 & 0.568 \\
\hline \multirow{2}{*}{ Jul } & I & 0.199 & 0.642 & 1.695 & 0.688 & 0.738 & 0.674 & 0.229 \\
\hline & II & 0.217 & 0.769 & 1.924 & 0.817 & 0.875 & 0.798 & 0.336 \\
\hline \multirow{2}{*}{ Agust } & $\mathrm{I}$ & 0.175 & 0.975 & 2.346 & 0.922 & 1.101 & 0.911 & 0.393 \\
\hline & II & 0.190 & 0.636 & 1.581 & 0.606 & 0.683 & 0.603 & 0.303 \\
\hline
\end{tabular}

Tabel 10: Hasil Neraca Air Sebelum di Optimasi Kondisi 80\%

\begin{tabular}{|c|c|c|c|c|c|c|c|c|}
\hline \multirow{4}{*}{ Bulan } & \multirow{4}{*}{$\operatorname{Tr}$} & \multirow{4}{*}{$\begin{array}{c}\text { Ketersediaan } \\
\text { Air Irigasi } \\
\left(\mathrm{m}^{3} / \text { detik }\right)\end{array}$} & \multicolumn{6}{|c|}{ Kebutuhan Air Irigasi } \\
\hline & & & \multicolumn{6}{|c|}{$\left(\mathrm{m}^{3} /\right.$ detik $)$} \\
\hline & & & \multicolumn{6}{|c|}{ Sebelum Optimasi } \\
\hline & & & Eksisting & Alternatif 1 & Alternatif 2 & Alternatif 3 & Alternatif 4 & Alternatif 5 \\
\hline \multirow{2}{*}{ Sept } & $\mathrm{I}$ & 1.044 & 0.692 & 1.694 & 0.356 & 0.782 & 0.403 & 0.625 \\
\hline & II & 1.151 & 1.324 & 3.337 & 0.315 & 1.655 & 0.359 & 1.324 \\
\hline \multirow{2}{*}{ Okt } & I & 1.312 & 1.416 & 3.606 & 0.383 & 1.756 & 0.419 & 1.756 \\
\hline & II & 1.312 & 0.974 & 2.509 & 0.671 & 1.167 & 0.671 & 1.167 \\
\hline \multirow{2}{*}{ Nov } & I & 1.374 & 0.706 & 1.885 & 0.746 & 0.799 & 0.746 & 0.799 \\
\hline & II & 1.700 & 0.818 & 2.091 & 0.859 & 0.912 & 0.859 & 0.912 \\
\hline \multirow{2}{*}{ Des } & $\mathrm{I}$ & 1.641 & 0.786 & 2.094 & 0.813 & 0.866 & 0.813 & 0.866 \\
\hline & II & 1.658 & 0.531 & 1.443 & 0.527 & 0.554 & 0.527 & 0.554 \\
\hline \multirow{2}{*}{ Jan } & $\mathrm{I}$ & 1.473 & 0.712 & 1.719 & 0.363 & 0.659 & 0.363 & 0.821 \\
\hline & II & 1.404 & 1.356 & 3.310 & 0.298 & 1.344 & 0.298 & 1.674 \\
\hline \multirow{2}{*}{ Feb } & I & 1.271 & 1.444 & 3.558 & 0.377 & 1.444 & 0.377 & 1.809 \\
\hline & II & 1.277 & 1.050 & 2.527 & 0.736 & 1.050 & 0.736 & 1.318 \\
\hline \multirow{2}{*}{ Mar } & I & 1.168 & 0.503 & 1.185 & 0.510 & 0.503 & 0.510 & 0.621 \\
\hline & II & 1.295 & 0.657 & 1.459 & 0.696 & 0.657 & 0.696 & 0.803 \\
\hline \multirow{2}{*}{ Apr } & I & 1.256 & 0.807 & 2.085 & 0.992 & 0.806 & 0.992 & 0.990 \\
\hline & II & 1.509 & 0.657 & 1.617 & 0.796 & 0.657 & 0.796 & 0.767 \\
\hline \multirow{2}{*}{ Mei } & I & 1.364 & 0.737 & 1.779 & 0.449 & 0.737 & 0.449 & 0.885 \\
\hline & II & 1.607 & 1.264 & 3.204 & 0.272 & 1.263 & 0.272 & 1.579 \\
\hline \multirow{2}{*}{ Jun } & I & 1.565 & 1.269 & 3.299 & 0.236 & 1.576 & 0.236 & 1.179 \\
\hline & II & 1.185 & 0.849 & 2.193 & 0.532 & 1.027 & 0.530 & 0.568 \\
\hline \multirow{2}{*}{ Jul } & I & 1.403 & 0.642 & 1.695 & 0.688 & 0.738 & 0.674 & 0.229 \\
\hline & II & 1.185 & 0.769 & 1.924 & 0.817 & 0.875 & 0.798 & 0.336 \\
\hline \multirow{2}{*}{ Agust } & $\mathrm{I}$ & 0.862 & 0.975 & 2.346 & 0.922 & 1.101 & 0.911 & 0.393 \\
\hline & II & 0.596 & 0.636 & 1.581 & 0.606 & 0.683 & 0.603 & 0.303 \\
\hline
\end{tabular}


Tabel 11: Hasil Neraca Air Sebelum di Optimasi kondisi $75 \%$

\begin{tabular}{|c|c|c|c|c|c|c|c|c|}
\hline \multirow{4}{*}{ Bulan } & \multirow{4}{*}{$\operatorname{Tr}$} & \multirow{4}{*}{$\begin{array}{c}\text { Ketersediaan } \\
\text { Air Irigasi } \\
\text { (m³/detik) }\end{array}$} & \multicolumn{6}{|c|}{ Kebutuhan Air Irigasi } \\
\hline & & & \multicolumn{6}{|c|}{$\left(\mathrm{m}^{3} /\right.$ detik $)$} \\
\hline & & & \multicolumn{6}{|c|}{ Sebelum Optimasi } \\
\hline & & & Eksisting & Alternatif 1 & Alternatif 2 & Alternatif 3 & Alternatif 4 & Alternatif 5 \\
\hline \multirow{2}{*}{ Sept } & $\mathrm{I}$ & 1.422 & 0.692 & 1.694 & 0.356 & 0.782 & 0.403 & 0.625 \\
\hline & II & 1.422 & 1.324 & 3.337 & 0.315 & 1.655 & 0.359 & 1.324 \\
\hline \multirow{2}{*}{ Okt } & I & 1.338 & 1.416 & 3.606 & 0.383 & 1.756 & 0.419 & 1.756 \\
\hline & II & 1.344 & 0.974 & 2.509 & 0.671 & 1.167 & 0.671 & 1.167 \\
\hline \multirow{2}{*}{ Nov } & $\mathrm{I}$ & 1.531 & 0.706 & 1.885 & 0.746 & 0.220 & 0.746 & 0.799 \\
\hline & II & 1.849 & 0.818 & 2.091 & 0.859 & 0.912 & 0.859 & 0.912 \\
\hline \multirow{2}{*}{ Des } & I & 1.828 & 0.786 & 2.094 & 0.813 & 0.866 & 0.813 & 0.866 \\
\hline & II & 1.658 & 0.531 & 1.443 & 0.527 & 0.554 & 0.527 & 0.554 \\
\hline \multirow{2}{*}{ Jan } & I & 1.748 & 0.712 & 1.719 & 0.363 & 0.659 & 0.363 & 0.821 \\
\hline & II & 1.578 & 1.356 & 3.310 & 0.298 & 1.344 & 0.298 & 1.674 \\
\hline \multirow{2}{*}{ Feb } & I & 1.404 & 1.444 & 3.558 & 0.377 & 1.444 & 0.377 & 1.809 \\
\hline & II & 1.285 & 1.050 & 2.527 & 0.736 & 1.050 & 0.736 & 1.318 \\
\hline \multirow{2}{*}{ Mar } & $\mathrm{I}$ & 1.349 & 0.503 & 1.185 & 0.510 & 0.503 & 0.510 & 0.621 \\
\hline & II & 1.323 & 0.657 & 1.459 & 0.696 & 0.657 & 0.696 & 0.803 \\
\hline \multirow{2}{*}{ Apr } & $\mathrm{I}$ & 1.467 & 0.807 & 2.085 & 0.992 & 0.806 & 0.992 & 0.990 \\
\hline & II & 1.561 & 0.657 & 1.617 & 0.796 & 0.657 & 0.796 & 0.767 \\
\hline \multirow{2}{*}{ Mei } & $\mathrm{I}$ & 1.390 & 0.737 & 1.779 & 0.449 & 0.737 & 0.449 & 0.885 \\
\hline & II & 1.675 & 1.264 & 3.204 & 0.272 & 1.263 & 0.272 & 1.579 \\
\hline \multirow{2}{*}{ Jun } & I & 1.584 & 1.269 & 3.299 & 0.236 & 1.576 & 0.236 & 1.179 \\
\hline & II & 1.217 & 0.849 & 2.193 & 0.532 & 1.027 & 0.530 & 0.568 \\
\hline \multirow{2}{*}{ Jul } & I & 1.677 & 0.642 & 1.695 & 0.688 & 0.738 & 0.674 & 0.229 \\
\hline & II & 1.217 & 0.769 & 1.924 & 0.817 & 0.875 & 0.798 & 0.336 \\
\hline \multirow{2}{*}{ Agust } & I & 1.422 & 0.975 & 2.346 & 0.922 & 1.101 & 0.911 & 0.393 \\
\hline & II & 1.422 & 0.636 & 1.581 & 0.606 & 0.683 & 0.603 & 0.303 \\
\hline
\end{tabular}

Tabel 12: Hasil Neraca Air Sebelum di Optimasi Kondisi 50\% dan 30\%

\begin{tabular}{|c|c|c|c|c|}
\hline \multirow{2}{*}{ Bulan } & \multirow{2}{*}{ Periode } & \multirow{2}{*}{$\begin{array}{c}\text { Ketersediaan Air Irigasi } 50 \% \\
\left(\mathrm{~m}^{3} / \text { detik }\right)\end{array}$} & \multirow{2}{*}{$\begin{array}{c}\text { Ketersediaan Air Irigasi } 30 \% \\
\left(\mathrm{~m}^{3} / \text { detik }\right)\end{array}$} & \multirow{2}{*}{$\begin{array}{c}\text { Kebutuhan Air Irigasi } \\
\left.\text { ( } \mathrm{m}^{3} / \text { detik }\right)\end{array}$} \\
\hline & & & & \\
\hline \multirow{2}{*}{ Sept } & I & 7.120 & 9.328 & 0.692 \\
\hline & II & 4.270 & 8.439 & 1.324 \\
\hline \multirow{2}{*}{ Okt } & I & 6.442 & 8.055 & 1.416 \\
\hline & II & 5.190 & 11.461 & 0.974 \\
\hline \multirow{2}{*}{ Nov } & I & 8.065 & 13.595 & 0.706 \\
\hline & II & 11.832 & 16.229 & 0.818 \\
\hline \multirow{2}{*}{ Des } & I & 12.903 & 17.603 & 0.786 \\
\hline & II & 15.061 & 16.613 & 0.531 \\
\hline \multirow{2}{*}{ Jan } & I & 12.410 & 14.630 & 0.712 \\
\hline & II & 10.789 & 12.342 & 1.356 \\
\hline \multirow{2}{*}{ Feb } & I & 11.954 & 13.090 & 1.444 \\
\hline & II & 11.997 & 13.670 & 1.050 \\
\hline \multirow{2}{*}{ Mar } & I & 10.576 & 12.858 & 0.503 \\
\hline & II & 10.691 & 13.103 & 0.657 \\
\hline \multirow{2}{*}{ Apr } & I & 10.337 & 11.785 & 0.807 \\
\hline & II & 12.156 & 13.066 & 0.657 \\
\hline \multirow{2}{*}{ Mei } & I & 13.182 & 14.271 & 0.737 \\
\hline & II & 13.189 & 13.962 & 1.264 \\
\hline \multirow{2}{*}{ Jun } & I & 14.141 & 15.029 & 1.269 \\
\hline & II & 12.710 & 13.513 & 0.849 \\
\hline \multirow{2}{*}{ Jul } & I & 13.392 & 14.527 & 0.642 \\
\hline & II & 12.710 & 13.513 & 0.769 \\
\hline \multirow{2}{*}{ Agust } & I & 12.409 & 12.729 & 0.975 \\
\hline & II & 9.934 & 10.897 & 0.636 \\
\hline
\end{tabular}


Dari analisis pada tabel 9 - 12 merupakan necara air PTT Eksisting sampai dengan Alternatif 5 berdasarkan debit andalan 97\%, 80\%, 75\%, 50\% dan 30\%. Untuk debit andalan 97\% dan 80\% membuktikan bahwa kebutuhan air irigasi dengan PPT Eksisting sampai dengan alternatif 5 untuk ketersediaan airnya tidak mencukupi untuk memenuhi kebutuhan air irigasi. Untuk debit andalan $75 \%$ kondisi eksisting, alternatif 1 , alternatif 3 dan alternatif 5 terjadi defisit air sehingga tidak tercukupi untuk memenuhi kebutuhan air irigasi, untuk alternatif 2 dan alternatif 4 kondisi terpenuhi. Untuk debit andalan 50\% dan 30\% kondisi ketersediaan air dapat memenuhi kebutuhan air irigasi.

Berdasarkan permasalahan diatas, maka perlu dilakukan optimasi pemanfaatan air agar ketersediaan air yang ada dapat mencukupi kebutuhan air irigasi sehingga didapatkan hasil keuntungan produksi pertanian yang optimal. Untuk kondisi ketersediaan dan kebutuhan air yang terpenuhi. Tidak dilakukan optimasi dikarenakan kondisinya ketersediaan air lebih tinggi dari pada kebutuhan air yang telah direncanakan. [10]

\subsection{Hasil Neraca air Setelah di Optimasi}

Setelah mengetahui luas lahan optimal pada masing - masing tanaman untuk setiap musim tanam, dalam neraca air ini akan di analisis hasil setelah dilakukan optimasi pada pola tata tanam eksisting serta 5 pola tata tanam alternatif. Untuk lebih jelasnya neraca air dapat dilihat pada tabel berikut ini.

Tabel 13: Hasil Neraca Air Sesudah Optimasi Kondisi 97\%

\begin{tabular}{|c|c|c|c|c|c|c|c|c|}
\hline \multirow{4}{*}{ Bulan } & \multirow{4}{*}{$\operatorname{Tr}$} & \multirow{4}{*}{$\begin{array}{c}\begin{array}{c}\text { Ketersediaan } \\
\text { Air Irigasi }\end{array} \\
\left(\mathrm{m}^{3} / \text { detik }\right)\end{array}$} & \multicolumn{6}{|c|}{ Kebutuhan Air Irigasi } \\
\hline & & & \multicolumn{6}{|c|}{$\left(\mathrm{m}^{3} /\right.$ detik $)$} \\
\hline & & & \multicolumn{6}{|c|}{ Sesudah Optimasi } \\
\hline & & & Eksisting & Alternatif 1 & Alternatif 2 & Alternatif 3 & Alternatif 4 & Alternatif 5 \\
\hline \multirow{2}{*}{ Sept } & I & 0.129 & 0.123 & 0.076 & 0.129 & 0.072 & 0.055 & 0.072 \\
\hline & II & 0.315 & 0.000 & 0.149 & 0.066 & 0.152 & 0.051 & 0.152 \\
\hline \multirow{2}{*}{ Okt } & I & 0.161 & 0.021 & 0.161 & 0.046 & 0.161 & 0.063 & 0.161 \\
\hline & II & 0.118 & 0.074 & 0.112 & 0.081 & 0.107 & 0.111 & 0.107 \\
\hline \multirow{2}{*}{ Nov } & I & 0.124 & 0.124 & 0.084 & 0.090 & 0.073 & 0.124 & 0.073 \\
\hline & II & 0.163 & 0.161 & 0.094 & 0.104 & 0.084 & 0.142 & 0.084 \\
\hline \multirow{2}{*}{ Des } & I & 0.229 & 0.170 & 0.094 & 0.098 & 0.080 & 0.135 & 0.080 \\
\hline & II & 0.425 & 0.161 & 0.065 & 0.064 & 0.051 & 0.087 & 0.051 \\
\hline \multirow{2}{*}{ Jan } & I & 0.863 & 0.555 & 0.499 & 0.291 & 0.475 & 0.291 & 0.439 \\
\hline & II & 0.968 & 0.961 & 0.960 & 0.239 & 0.966 & 0.239 & 0.914 \\
\hline \multirow{2}{*}{ Feb } & I & 1.033 & 1.033 & 1.033 & 0.302 & 1.033 & 0.302 & 1.033 \\
\hline & II & 1.104 & 0.788 & 0.733 & 0.589 & 0.742 & 0.589 & 0.807 \\
\hline \multirow{2}{*}{ Mar } & I & 0.903 & 0.440 & 0.344 & 0.408 & 0.341 & 0.408 & 0.451 \\
\hline & II & 0.836 & 0.548 & 0.423 & 0.557 & 0.451 & 0.557 & 0.539 \\
\hline \multirow{2}{*}{ Apr } & I & 1.081 & 0.611 & 0.605 & 0.793 & 0.568 & 0.793 & 0.587 \\
\hline & II & 1.294 & 0.492 & 0.469 & 0.636 & 0.464 & 0.636 & 0.397 \\
\hline \multirow{2}{*}{ Mei } & I & 1.050 & 0.528 & 0.516 & 0.359 & 0.526 & 0.359 & 0.458 \\
\hline & II & 1.325 & 0.845 & 0.930 & 0.218 & 0.917 & 0.218 & 0.817 \\
\hline \multirow{2}{*}{ Jun } & I & 1.050 & 0.014 & 0.247 & 0.017 & 0.251 & 0.000 & 0.450 \\
\hline & II & 0.217 & 0.050 & 0.164 & 0.062 & 0.164 & 0.000 & 0.217 \\
\hline \multirow{2}{*}{ Jul } & I & 0.199 & 0.097 & 0.127 & 0.119 & 0.118 & 0.000 & 0.088 \\
\hline & II & 0.217 & 0.127 & 0.144 & 0.156 & 0.139 & 0.000 & 0.128 \\
\hline \multirow{2}{*}{ Agust } & I & 0.175 & 0.175 & 0.175 & 0.175 & 0.175 & 0.000 & 0.150 \\
\hline & II & 0.190 & 0.167 & 0.118 & 0.167 & 0.109 & 0.000 & 0.116 \\
\hline
\end{tabular}


Tabel 14: Hasil Neraca Air Sesudah Optimasi Kondisi $80 \%$

\begin{tabular}{|c|c|c|c|c|c|c|c|c|}
\hline \multirow{4}{*}{ Bulan } & \multirow{4}{*}{$\operatorname{Tr}$} & \multirow{4}{*}{$\begin{array}{c}\text { Ketersediaan } \\
\text { Air Irigasi }\end{array}$} & \multicolumn{6}{|c|}{ Kebutuhan Air Irigasi } \\
\hline & & & \multicolumn{6}{|c|}{$\left(\mathrm{m}^{3} /\right.$ detik $)$} \\
\hline & & & \multicolumn{6}{|c|}{ Sesudah Optimasi } \\
\hline & & & Eksisting & Alternatif 1 & Alternatif 2 & Alternatif 3 & Alternatif 4 & Alternatif 5 \\
\hline \multirow{2}{*}{ Sept } & $\mathrm{I}$ & 1.044 & 0.608 & 0.585 & 0.295 & 0.544 & 0.303 & 0.544 \\
\hline & II & 1.151 & 1.151 & 1.151 & 0.273 & 1.151 & 0.281 & 1.151 \\
\hline \multirow{2}{*}{ Okt } & I & 1.312 & 1.232 & 1.244 & 0.340 & 1.221 & 0.349 & 1.221 \\
\hline & II & 1.312 & 0.850 & 0.866 & 0.596 & 0.811 & 0.612 & 0.811 \\
\hline \multirow{2}{*}{ Nov } & I & 1.374 & 0.620 & 0.650 & 0.662 & 0.153 & 0.681 & 0.556 \\
\hline & II & 1.700 & 0.719 & 0.721 & 0.763 & 0.635 & 0.784 & 0.635 \\
\hline \multirow{2}{*}{ Des } & I & 1.641 & 0.691 & 0.722 & 0.721 & 0.603 & 0.741 & 0.603 \\
\hline & II & 1.658 & 0.469 & 0.498 & 0.468 & 0.385 & 0.481 & 0.385 \\
\hline \multirow{2}{*}{ Jan } & I & 1.473 & 0.634 & 0.614 & 0.291 & 0.577 & 0.291 & 0.570 \\
\hline & II & 1.404 & 1.191 & 1.182 & 0.239 & 1.179 & 0.239 & 1.167 \\
\hline \multirow{2}{*}{ Feb } & I & 1.271 & 1.271 & 1.271 & 0.302 & 1.271 & 0.302 & 1.271 \\
\hline & II & 1.277 & 0.930 & 0.903 & 0.589 & 0.930 & 0.589 & 0.938 \\
\hline \multirow{2}{*}{ Mar } & I & 1.168 & 0.456 & 0.423 & 0.408 & 0.456 & 0.408 & 0.457 \\
\hline & II & 1.295 & 0.591 & 0.521 & 0.557 & 0.591 & 0.557 & 0.582 \\
\hline \multirow{2}{*}{ Apr } & I & 1.256 & 0.715 & 0.745 & 0.793 & 0.715 & 0.793 & 0.700 \\
\hline & II & 1.509 & 0.581 & 0.578 & 0.636 & 0.581 & 0.636 & 0.530 \\
\hline \multirow{2}{*}{ Mei } & I & 1.364 & 0.648 & 0.635 & 0.359 & 0.648 & 0.359 & 0.611 \\
\hline & II & 1.607 & 1.102 & 1.144 & 0.218 & 1.102 & 0.218 & 1.091 \\
\hline \multirow{2}{*}{ Jun } & I & 1.565 & 1.117 & 1.212 & 0.226 & 1.234 & 0.220 & 1.179 \\
\hline & II & 1.185 & 0.748 & 0.806 & 0.506 & 0.804 & 0.487 & 0.567 \\
\hline \multirow{2}{*}{ Jul } & I & 1.403 & 0.567 & 0.623 & 0.646 & 0.577 & 0.611 & 0.229 \\
\hline & II & 1.185 & 0.679 & 0.707 & 0.763 & 0.685 & 0.718 & 0.335 \\
\hline \multirow{2}{*}{ Agust } & I & 0.862 & 0.862 & 0.862 & 0.862 & 0.862 & 0.811 & 0.393 \\
\hline & II & 0.596 & 0.563 & 0.580 & 0.555 & 0.535 & 0.508 & 0.303 \\
\hline
\end{tabular}

Tabel 15: Hasil Neraca Air Sesudah Optimasi Kondisi $75 \%$

\begin{tabular}{|c|c|c|c|c|c|c|c|c|}
\hline \multirow{4}{*}{ Bulan } & \multirow{4}{*}{$\operatorname{Tr}$} & \multirow{4}{*}{$\begin{array}{c}\text { Ketersediaan } \\
\text { Air Irigasi } \\
\text { (m³/detik) }\end{array}$} & \multicolumn{6}{|c|}{ Kebutuhan Air Irigasi } \\
\hline & & & \multicolumn{6}{|c|}{$\left(\mathrm{m}^{3} /\right.$ detik $)$} \\
\hline & & & \multicolumn{6}{|c|}{ Sebelum Optimasi } \\
\hline & & & Eksisting & Alternatif 1 & Alternatif 2 & Alternatif 3 & Alternatif 4 & Alternatif 5 \\
\hline \multirow{2}{*}{ Sept } & I & 1.422 & 0.635 & 0.628 & 0.356 & 0.595 & 0.403 & 0.595 \\
\hline & II & 1.422 & 1.254 & 1.237 & 0.315 & 1.261 & 0.359 & 1.261 \\
\hline \multirow{2}{*}{ Okt } & $\mathrm{I}$ & 1.338 & 1.338 & 1.338 & 0.383 & 1.338 & 0.419 & 1.338 \\
\hline & II & 1.344 & 0.910 & 0.931 & 0.671 & 0.889 & 0.671 & 0.889 \\
\hline \multirow{2}{*}{ Nov } & $\mathrm{I}$ & 1.531 & 0.649 & 0.699 & 0.746 & 0.167 & 0.746 & 0.609 \\
\hline & II & 1.849 & 0.748 & 0.776 & 0.859 & 0.695 & 0.859 & 0.695 \\
\hline \multirow{2}{*}{ Des } & $\mathrm{I}$ & 1.828 & 0.716 & 0.777 & 0.813 & 0.660 & 0.813 & 0.660 \\
\hline & II & 1.658 & 0.477 & 0.535 & 0.527 & 0.422 & 0.527 & 0.422 \\
\hline \multirow{2}{*}{ Jan } & $\mathrm{I}$ & 1.748 & 0.679 & 0.678 & 0.363 & 0.646 & 0.363 & 0.643 \\
\hline & II & 1.578 & 1.320 & 1.306 & 0.298 & 1.313 & 0.298 & 1.308 \\
\hline \multirow{2}{*}{ Feb } & $\mathrm{I}$ & 1.404 & 1.404 & 1.404 & 0.377 & 1.404 & 0.377 & 1.404 \\
\hline & II & 1.285 & 1.009 & 0.997 & 0.736 & 1.009 & 0.736 & 1.011 \\
\hline \multirow{2}{*}{ Mar } & $\mathrm{I}$ & 1.349 & 0.465 & 0.467 & 0.510 & 0.465 & 0.510 & 0.461 \\
\hline & II & 1.323 & 0.615 & 0.576 & 0.696 & 0.615 & 0.696 & 0.606 \\
\hline \multirow{2}{*}{ Apr } & $\mathrm{I}$ & 1.467 & 0.774 & 0.823 & 0.992 & 0.774 & 0.992 & 0.764 \\
\hline & II & 1.561 & 0.632 & 0.638 & 0.796 & 0.632 & 0.796 & 0.604 \\
\hline \multirow{2}{*}{ Mei } & I & 1.390 & 0.716 & 0.702 & 0.449 & 0.716 & 0.449 & 0.697 \\
\hline & II & 1.675 & 1.246 & 1.264 & 0.272 & 1.246 & 0.272 & 1.244 \\
\hline \multirow{2}{*}{ Jun } & I & 1.584 & 1.399 & 1.584 & 0.236 & 1.261 & 0.236 & 1.179 \\
\hline & II & 1.217 & 0.911 & 1.054 & 0.532 & 0.821 & 0.530 & 0.567 \\
\hline \multirow{2}{*}{ Jul } & $\mathrm{I}$ & 1.677 & 0.655 & 0.814 & 0.688 & 0.590 & 0.674 & 0.229 \\
\hline & II & 1.217 & 0.777 & 0.924 & 0.817 & 0.700 & 0.798 & 0.335 \\
\hline \multirow{2}{*}{ Agust } & $\mathrm{I}$ & 1.422 & 0.977 & 1.127 & 0.922 & 0.881 & 0.911 & 0.393 \\
\hline & II & 1.422 & 0.606 & 0.759 & 0.606 & 0.546 & 0.603 & 0.303 \\
\hline
\end{tabular}

Pada tabel 13 - 15 menunjukan bahwa setelah dilakukan optimasi, ketersediaan air dapat memenuhi semua kebutuhan air tanpa ada yang kekurangan. Hal ini disebabkan oleh pengaturan luasan lahan tiap tanaman yang tepat sehingga kebutuhan air irigasi tidak melonjak melebihi ketersediaan air yang ada. 


\section{Kesimpulan}

Dalam studi ini terdapat 1 pola tata tanam eksisting dan 5 alternatif yaitu dengan diawali penyiapan lahan di padi selama 30 hari dengan 2 periode masa tanam (15 harian). Bila dihubungkan antara $Q$ kebutuhan dan $\mathrm{Q}$ andalan dengan kondisi debit andalan 97\% pada pola tata tanam eksisting dan alternatif 3 total periode yang terpenuhi yaitu 33,3\%, alternatif 1 yaitu $0 \%$, alternatif 2 yaitu $50 \%$ alternatif 4 yaitu $45,83 \%$ dan alternatif 5 yaitu $25 \%$. Untuk kondisi debit andalan $80 \%$ periode yang terpenuhi pada pola tata tanam eksisting yaitu $79,18 \%$, alternatif 1 yaitu $4,18 \%$, alternatif 2 dan alternatif 4 yaitu 91,97 dan alternatif 3 yaitu $75 \%$ dan alternatif 5 yaitu $79,18 \%$. Sedangkan untuk debit andalan $75 \%$ periode yang terpenuhi pada eksisting yaitu $33,3 \%$, alternatif 1 yaitu $12,5 \%$, alternatif 2 dan alternatif 4 yaitu $100 \%$, alternatif 3 yaitu $87,5 \%$ dan alternatif 5 yaitu $83,3 \%$. Dengan menghitung pola tata eksisting total kebutuhan irigasi sebesar $1,864,009 \mathrm{~m}^{3}$ setelah di optimasi menjadi $714,030 \mathrm{~m}^{3}$, pola tata tanam alternatif 1 sebesar $4,677,575 \mathrm{~m}^{3}$ di optimasi $719,015 \mathrm{~m}^{3}$, pola tata tanam alternatif 2 sebesar 1,206,066 $\mathrm{m}^{3}$ di optimasi 492,219 $\mathrm{m}^{3}$, alternatif 3 sebesar 2,039,903 $\mathrm{m}^{3}$ di optimasi 710,263 , alternatif 4 sebesar $1,212,719 \mathrm{~m}^{3}$ di optimasi $445,832 \mathrm{~m}^{3}$ dan alternatif $5 \quad 1,924,790 \mathrm{~m}^{3}$ di optimasi menjadi $723,196 \mathrm{~m}^{3}$.

Setelah melewati tahap analisa, Q kebutuhan irigasi pola tata tanam 2 dan 4 pada debit andalan $75 \%$ sudah terpenuhi sebelum dilakukan optimasi. Pola tata tanam alternatif 2 memiliki keuntungan paling maksimal diantara 5 pola tata tana lainnya dengan keuntungan maksimum yaitu Rp32.969.542.295,00 pada kondisi debit andalan 97\%. Sedangkan pola tata tanam alternatif 4 memiliki keuntungan paling maksimal yaitu Rp49.682.562.315,00 pada kondisi debit andalan 80\%. dan yang terakhir pola tata tanam eksisting memiliki keuntungan paling maksimal yaitu Rp50.135.817.479,00 pada kondisi debit andalan $75 \%$.

\section{Daftar Pustaka}

[1] L. M. Limantara, Hidrologi Teknik Sumber Daya Air. Malang: Penerbit Citra, 2010.

[2] C. D. Soemarto, Hidrologi Teknik. Surabaya: Penerbit Usaha Nasional, 1987.

[3] Peraturan.go.id, 2021. [Online]. Available: https://peraturan.go.id/common/dokum en/ln/1982/pp23-1982.pdf. [Accessed: 14- Apr- 2021].

[4] C. Hazael, R. Sayekti dan T. Prayogo, "Studi Optimasi Pemanfaatan Air Irigasi Pada Daerah irigasi Kedungputri Kecamatan Paron Kabupaten Ngawi”, Jurnal Teknik Pengairan, Vol. 4, No. $1,2020$.

[5] A. Fathia, L. Montarcih dan S. Wahyuni, "Studi Perubahan Karakteristik Hidrologi (Debit Puncak dan Waktu Puncak) Akibat Perubahan Tata Guna Lahan di DAS Lesti dan DAS Gadang Kabupaten Malang”, Jurnal Teknologi dan Rekayasa Sumber Daya Air, Vol. 1, No. 2, pp. 453466, 2021.

[6] Sibima.pu.go.id, 2021. [Online]. Available: http://sibima.pu.go.id/pluginfile.php/8088/mod_re source/content/1/SDA-KP03-Spesifikasi\%20Teknis\%20Kriteria\%20PerencanaanBangunan\% 20Utama.pdf. [Accessed: 14- Apr- 2021].

[7] Suhardjono, Kebutuhan Air Tanaman. Malang: Penerbit Institut Teknologi Nasional, 1994.

[8] S. Sosrodarsono dan K. Takeda, Hidrologi untuk Pengairan. Jakarta: Penerbit PT. Paradyna Paramita, 1976.

[9] M. Bardan, Irigasi. Yogyakarta: Penerbit Graha Ilmu, 2014.

[10] F. Retnowati dan R. Sayekti. "Optimasi Pemanfaatan Air di Daerah Irigasi Tanggul Kabupaten Pasuruan Menggunakan Program Linier”, Jurnal Teknik Pengairan, Vol. 1, No. 2, 2018. 